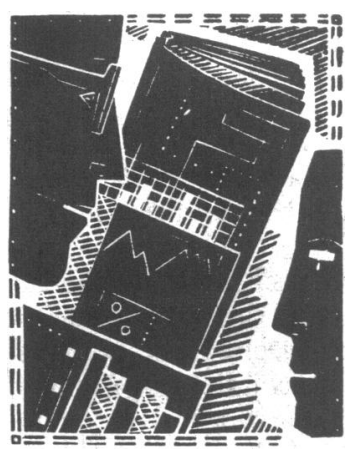

THIS WEEK . .

- In the first article Milne describes a retrospective study of how far certain standards of care were met for young children with sickle cell disease. The shortcomings disclosed lead him to conclude that to be effective, screening programmes should include careful plans for follow up.

- In the second article Kerrigan et al show by retrospective audit that widespread fears of unnecessary examinations and increased workload with open access gastroscopy are unfounded.

Wilson reports that completion of a second audit of cervical cytology programmes of practices of members of the
Vale of Trent faculty of the RCGP has disclosed improved performance compared with the first audit in 1985. The improvements include development of a practice policy, installation of computerised call and recall systems, and increased numbers of women having a smear in the previous first years. He suggests, however, that this probably reflects a widespread trend rather than participation in the first audit.

- Dr Baker, in the first commissioned article, deals with using audit to solve problems in general practice, and $\mathrm{Mr}$ Nixon, in the second, with defining essential hospital data.

\title{
Assessment of care of children with sickle cell disease: implications for neonatal screening programmes
}

\author{
R I G Milne
}

\begin{abstract}
Objective-To assess the quality of care provided by hospitals for young children with sickle cell disease.

Design-Retrospective survey.

Setting-Teaching hospital in London.

Patients - 31 Children (mean age 4 years 4 months, range 4 months to 7 years 5 months) born with sickle cell disease between 1978 and 1985 identified from Hospital Activity Analysis data, an outpatient diagnostic register, and registers of the haematology department. Eight had been diagnosed on neonatal screening and at least four of these had not been followed up.
\end{abstract}

Main outcome measures-Aspects of quality of outpatient care (blood testing, clinic attendance, and prophylactic drug treatment) and family care (adequate support and carers' knowledge about the disease) as assessed by reviewing the notes and administering a semistructured questionnaire to the carers, in relation to a devised list of standards deemed necessary to ensure achievement of the aims of screening.

Results-There were 93 outpatient attendances during the previous 12 months, but 13 children had not attended at least every six months and four not at all for more than a year. Only eight children had had three of the blood tests considered to be necessary for good care; three had had none. Prophylactic treatment with penicillin and folic acid was erratic; three children with sickle cell anaemia were not receiving regular prophylactic penicillin.

Implication-Diagnosis of sickle cell disease on neonatal screening must be linked with follow up to ensure optimal management.

\section{Introduction}

The case for neonatal screening for sickle cell disease is compelling, ${ }^{1-3}$ although its effectiveness has never been formally evaluated in a randomised controlled trial. One approach to its indirect evaluation, adopted in two studies from New York state in the early $1980 \mathrm{~s},{ }^{45}$ is to assume that screening can be only as effective as the care subsequently given to children identified on screening and to assess the quality of care by, for instance, determining whether prophylactic penicillin is taken regularly, which is crucial to reduce the incidence of pneumococcal infection. ${ }^{6}$

I followed the same approach in a study of children with sickle cell disease at a central London teaching hospital, most of whom had been identified outside the neonatal screening programme, which was new at the time. I sought to elucidate leave out the ability of the hospital to deliver care of sufficient quality for the new programme's aims - namely, to reduce the morbidity and mortality from sickle cell disease - was achievable.

\section{Patients and methods}

Children were said to have sickle cell disease if one of the sickle haemoglobinopathies (including HbSS and $\mathrm{HbSC}$ diseases as well as $\mathrm{HbS} / \mathrm{B}$ thalassaemia) had been diagnosed on haemoglobin electrophoresis. Children with sickle cell disease were entered into the study if they were born between 1978 and 1985 and if they were the hospital's responsibility, having been in its care at least once (whether as an inpatient or an outpatient or being born there) and without good evidence of being in the care of another hospital.

The standards of care I examined were those thought to be necessary to reduce morbidity and mortality from sickle cell disease by a combination of preventive and therapeutic measures. A list of standards was compiled after reviewing the literature and revised after discussions with all consultants concerned with the care of young children with sickle cell disease (box). It covered two main subjects of long term care: outpatient care (including blood tests, regular clinic attendance, and prophylactic drug treatment) and family care (including practical knowledge about sickle cell disease and adequate support); both were felt to be critical to successful follow up and to be, at least in part, the hospital's responsibility.

As no register of affected children was available I compiled one from Hospital Activity Analysis data from 1978 to 1984; an outpatient diagnostic register kept by consultants at the hospital from 1981 to 1986; a 
Agreed key standards necessary for care of young children (aged $>6$ months) with sickle cell disease

Outpatient attendance

All children to be seen at least every six months ${ }^{\star}$

\section{Outpatient care}

All carers to be given a diagnostic card ${ }^{\star}$

Full blood count and reticulocyte count at least once a year*

Determination of blood group ${ }^{\star}$

Red cell genotyping

Measurement of weight and height at least once a year ${ }^{\star}$

Letter to be sent to child's general practitioner at least: After diagnosis

After every admission

Every year, to describe follow up

\section{Drug treatment}

All children to be prescribed and given penicillin and folic acid in appropriate doses ${ }^{\star}$

Carers to know the names of drugs and something of their purposes $\star$

$\star$ Standards discussed in text

ward diagnostic register from 1982 to 1985; and registers of the haematology department from 1978 to 1986. Children whose notes showed that they were currently under the care of another hospital were excluded. The completeness of the register was checked by searching the haemoglobin electrophoresis register (containing results of neonatal screening from 1984 onwards) and by reviewing the death certificates of children living in the district who died aged under 5 years between 1980 and 1985 .

I completed a proforma to assess outpatient care, devised from the list of standards, after reviewing the notes and administered a semistructured interview questionnaire devised to find out sociodemographic details about the children and to assess aspects of family care. Questions were also asked about genetic aspects of the disease, which were not originally included in the list of standards.

Ethical approval for the study was obtained from the hospital's ethical committee. The children's parents or guardians (carers) were contacted by post, up to three times, asking permission for an interview at their home. The proformas and the questionnaire were completed in late spring 1986.

\section{Results}

Thirty one children identified as the current responsibility of the hospital were entered into the study, and 25 carers, comprising 23 mothers and 2 grandmothers, representing 26 of the children agreed to be interviewed. The register did not include all children who might have been eligible for entry into the study. Review of the death certificates disclosed one name which had not appeared in any of the sources used to compile the register, but it was not considered appropriate to enter this child into the study. Also, four named children, born in 1984-5, though identified from the haemoglobin electrophoresis register as having sickle cell anaemia on neonatal screening, had never been followed up as outpatients. By comparison only four children with sickle cell anaemia born in those years had been followed up after diagnosis.

Table I summarises the demographic and diagnostic characteristics of the children. Their ages ranged from 4 months to 7 years 5 months (mean age 4 years 4 months); in eight their disease had been diagnosed on neonatal screening, in six on other screening, and in 17 during investigation of a clinical problem. All but two had been born in London; 22 had sickle cell anaemia.

\section{OUTPATIENT ATTENDANCE AND CARE}

The 31 children had attended the outpatient departments (paediatric and haematology) in all 93 times in the previous 12 months. Thirteen, however, did not meet the standard of having attended at least every six months for the previous year and four had not been seen at a clinic for over a year.

Of the carers of 26 of the children, nine said they had been given a diagnostic card (with the child's name and detailed result of haemoglobin electrophoresis), which all nine still had. The numbers of children who had three of the blood tests deemed necessary for good care in the list of minimum standards (full blood count and reticulocyte count in the past year and blood group (ever)) were 27, 22, and 11, respectively. Only eight of the 31 had had all three tests; three had had none. Regular weighing is an important tool in paediatrics, but 13 children did not meet the standard of having been weighed at least twice in the previous two years; seven of the 31 children had not been weighed at all in that time.

\section{PROPHYLACTIC DRUGS}

Three aspects of prophylactic drug treatment were examined: that penicillin (or erythromycin in the case of allergy to penicillin) and folic acid should be prescribed; that they should be given at the right frequencies (penicillin twice daily and folic acid once daily); and that their names should be readily recalled by the carers. Only $12(46 \%)$ of the 26 children interviewed (11 $(61 \%)$ of the 18 children with sickle cell anaemia) met all of these criteria. Of the 31 children in the study $25(81 \%)$ were prescribed penicillin and $29(94 \%)$ folic acid. Of 24 carers of children in the second group who were interviewed, three could not remember the name of the drug; three gave it less than once a day.

The carers of 18 children with sickle cell anaemia (those at highest risk therefore of pneumococcal infection) were interviewed. Seven children (39\%) seemed inadequately protected against pneumococcal infection; two were receiving no prophylactic pencillin at all (one because the drug had not been prescribed), another was receiving prophylactic penicillin only about one month in four, and four were said not to receive penicillin for 24 hours or more at least once a week.

\section{GENETIC ASPECTS}

Carers were asked three questions about genetic aspects of the disease: its cause ("Why do you think she or he has sickle cell disease?"); its course ("Will it ever go away entirely?"); and the risk to future children ("If you had any more children, is there a chance they might have sickle cell disease"). Incorrect answers included "don't know," "don't know" or "yes," and "don't know" or "no," respectively. Sixteen of the 25 carers failed to answer all three questions correctly, and 14 said that no

TABLE I-Demographic and diagnostic characteristics of 31 children in study

\begin{tabular}{lccc}
\hline & $\begin{array}{c}\text { Boys } \\
(\mathbf{n}=16)\end{array}$ & $\begin{array}{c}\text { Girls } \\
(\mathrm{n}=15)\end{array}$ & $\begin{array}{c}\text { Total } \\
(\mathrm{n}=31)\end{array}$ \\
\hline HbSS & \multicolumn{2}{c}{ Haemoglobinopathy } & \\
HbSC & 12 & 10 & 22 \\
HbS $\beta^{\circ}$ thalassaemia & 4 & 4 & 8 \\
& 0 & 1 & 1 \\
African & Ethnic origin & & \\
Caribbean & 10 & 9 & 19 \\
Not interviewed & 2 & 5 & 7 \\
& 4 & 1 & 5 \\
\hline
\end{tabular}


one had ever talked to them about these aspects of the disease.

\section{Discussion}

It would be wrong to judge that the standards against which care was examined were unrealistic. Each was met for at least a third of the children and if they had been met for all the workload would not have increased greatly. For instance, if all children had attended outpatient clinics at least twice in the previous year the number of outpatient appointments for sickle cell disease in that time would have increased by only 13/93 $(14 \%)$. Nor were the standards unnecessary. There is a strong a priori argument that if screening for sickle cell disease is not followed by appropriate care for all those with the disease it is unlikely to benefit fully those affected.

A third of children were not being seen as outpatients as often as they should have been, representing a loss of the opportunities offered by attendance..$^{2378}$ There was no evidence that they were being seen instead in primary care. This shortfall is similar to that reported from New York state, ${ }^{5}$ where five of 14 young children with sickle cell disease were not receiving "adequate medical care" (defined as having a regular doctor, keeping appointments, and promptly reporting symptoms). There were also shortcomings in the content of outpatient care. More than half the children had never had their blood grouped, and one in eight had no record of a recent full blood count. Most children had never been given a diagnostic card (cards are useful as not all carers remember the name of their child's haemoglobinopathy). ${ }^{45} \mathrm{~A}$ national scheme to issue cards to everyone who has been tested for haemoglobinopathy has recently been promoted by the Department; of Health. ${ }^{9}$

Prescribing prophylactic penicillin is crucial if neonatal screening is to benefit young children with sickle cell disease. ${ }^{1-310}$ I identified shortcomings in medical care (children not being prescribed prophylactic drugs) and family care (carers not knowing the names of the drugs or giving them incorrectly). It might be considered that the standards of care set in the study were too strict and that effort should be concentrated on children with HbSS disease (although those with $\mathrm{HbSC}$ disease may also have an increased incidence of pneumococcal infection " a third of the children with sickle cell anaemia interviewed (seven of 18) were regularly without penicillin for a day or longer and were probably inadequately protected against pneumoccal infection. ${ }^{12}$ For these children much of the value of having had their sickle cell disease diagnosed at birth was lost. Some of the benefit of prescribing prophylactic penicillin may derive from its availability at home and being readily used in the event of a febrile illness. ${ }^{16}$ Even with this optimistic interpretation, however, two children were unprotected.

Other results are no more encouraging. Griffiths et al reported that in Birmingham in an unstated proportion of children prophylactic penicillin was not accepted after neonatal screening. ${ }^{13}$ In one of the studies in New York state 11 of 18 parents did not recall being given any advice about pneumococcus prophylaxis, ${ }^{+}$and in the other only four of 14 children received prophylactic penicillin before first symptoms. ${ }^{5}$ The greater use of prophylactic penicillin in this study might be related to the diagnosis of sickle cell disease on neonatal screening in a lower proportion of children than in American studies $(45 \%$ v $100 \%)$. Other explanations include changes in usual paediatric practice during the years between the studies or differences in provision of health care.

Carers should surely have some understanding of the genetics of sickle cell disease, ${ }^{81+16}$ though this was not specified in the standards. It was disturbing that fewer than half the carers could answer all three questions about the genetics of the disease correctly and that fewer than half said that anyone had ever discussed such subjects with them. These results are no better than those from the United States. Warren et al found that 14 of 15 carers thought that the disease was inherited and that future children might be affected, ${ }^{+}$ and Rowley and Huntzinger reported that nine of 14 carers had been given genetic counselling.

My study examined the care given only to children identified from hospital sources. As these sources were incomplete some affected children known to the hospital will have been missed (particularly those born before 1981, who would have had most contact with the hospital in the years least covered by the sources examined). Furthermore, a community study might have identified two more groups who should have been the responsibility of the hospital. Firstly, some children with a doctor's diagnosis of sickle cell disease will never have received care at the hospital: in this group were the child who had died, whose name was not in the sources used, and the four children whose disease was diagnosed on neonatal screening and who were not followed up. Secondly, some children, an unknown number, in the hospital's catchment population will never even have had their disease diagnosed. Nevertheless, these selection biases do not weaken the central conclusion of the study as the children missed seemed likely to have received worse care than those identified. It is also important that the register of affected children compiled in the study was more complete than any of its constituent sources, none of which included more than $60 \%$ of the study children. The absence of such a register in usual practice and the difficulties experienced in compiling one make it hard to ensure adequate follow up for all children identified and to monitor that provided.

There is no reason to suppose that the care the individual children received was any worse than that received elsewhere. The problem lies more in the effectiveness of the care received by the whole population of young children with sickle cell disease. To be effective such care must be carefully organised, in a proactive and systematic way. This conclusion is not new. Many in the past 15 years have observed that screening for sickle cell disease will not achieve its full potential without a programme that links follow up with diagnosis, ${ }^{3-6} 1_{18}$ (as for any disease ${ }^{19}$ ). Yet this study suggests that it remains as difficult as ever to offer well organised and systematic follow up to every baby born with sickle cell disease. It will be crucial to develop such a system as an integral part of any screening programme if we are to achieve "optimal management of sickle cell disease from the time of birth." 20

I thank Professor W W Holland and Dr P Burney, department of community medicine, for their advice in planning and carrying out the study; Dr Burney for his help in preparing this paper; the paediatricians and haematologists, particularly for their help in compiling the list of standards and for allowing me to examine their patients' notes; and Helen Gee and Wendy Weller for typing.

1 Gaston $\mathrm{MH}$, Verter JI, Woods G, at al. Prophylaxis with oral penicillin in children with sickle cell anemia. $N$ Engl 7 Med 1986;314:1593-9.

2 Anonymous Penicillin prophylaxis for babies with sickle cell disease [Editorial]. Lancet 1986;ii: 1432-3.

3 Vichinksy E, Hurst D, Earles A, Kleman K, Lubin B. Newborn screening for sickle cell disease: effect on mortality. Pediatrics 1988;81:749-55.

4 Warren NS, Carter TP, Humbert JR, Rowley PT. Newborn screening for hemoglobinopathies in New York state: Experience of physicians and parents of affected children. 7 Pediatr 1982;100:373-7.

5 Rowley PT, Huntzinger DJ. Newborn sickle cell screening. Am 7 Dis Child 1983;137:341-5.

6 Powars D, Overturf G. Penicillin in sickle cell anemia. Am $\mathcal{f}$ Dis Child 1987;141:250-2.

7 Buchanan GR, Siegel JD, Smith SJ, DePasse B. Oral penicillin prophylaxis in 
children with impaired splenic function: a study of compliance. Pediatrics 1982;70:926-30.

8 Black J, Laws S. Living with sickle cell disease. London: Sickle Cell Society, East London Branch, 1986

9 Letter from Chief Medical, Nursing and Dental Officers. Haemoglobinopathy cards. London: Department of Health and Social Security. 1988. (PL/CMO (88) 11 )

10 John AB, Ramlal A, Jackson H, Maude GH, Sharma AW, Serjeant GR. Prevention of pneumococcal infection in children with homozygous sickle cell disease. BrMed f 1984;288:1567-70.

11 Buchanan GR, Smith SJ, Holtkamp CA, Fuseler JP. Bacterial infection and splenic reticuloendothelial function in children with hemoglobin SC disease. Pediatrics 1983;72:93-8.

12 Buchanan GR, Smith SJ. Pneumococcal septicemia despite pneumococcal vaccine and prescription of penicillin prophylaxis in children with sickle cell anemia. Am $\mathcal{J}$ Dis Child 1986;140:428-32.

13 Griffiths PD, Mann JR, Darbyshire PJ, Green A. Evaluation of eight and a half years of neonatal screening for haemoglobinopathies in Birmingham. BrMed f 1988:296:1583-5.
14 Horn MEC, Dick MC, Frost B, et al. Neonatal screening for sickle cell diseases in Camberwell: results and recommendations of a two year pilot study. BrMed f 1986;292:737-40.

15 Rowley PT. Newborn screening for sickle cell disease. Benefits and burdens. N Y State F Med 1978;78:42-4

16 Grover R, Wethers D, Shadidi S, Grossi M, Goldberg D, Davidow B. Evaluation of the expanded newborn screening program in New York City. Pediatrics 1978:61:740-9.

17 O'Brien RT, McIntosh S, Gregg TA, Pearson HA. Prospective study of sickle cell anemia in infancy. F Pediatr 1976;89:205-10.

18 Brozovic M, Anionwu E. Sickle cell disease in Britain. I Clin-Patho 1984;37:1321-6.

19 Cochrane AL, Holland WW. Validation of screening procedures. Br Med Bull $1971 ; 27: 1-8$.

20 Franklin IM. Services for sickle cell disease: unified approach needed. Br Med $\mathcal{f}$ 1988;296:592.

(Accepted 11 October 1989)

\title{
Open access gastroscopy: Too much to swallow?
}

\author{
D D Kerrigan, S R Brown, G H Hutchinson
}

\begin{abstract}
Objectives-To ascertain the proportion of endoscopic examinations with normal findings in patients referred for gastroscopy through hospital medical staff or directly by their general practitioner and to assess the likely effect of targeting endoscopy in older patients.
\end{abstract}

Design-Retrospective audit of the gastroscopy practice of one consultant from 1986 to 1988 from information recorded on a standard form completed at the time of the examination, which contained details of patients, their endoscopic findings, and mode of referral (open access or clinic).

Setting-One district general hospital.

Patients - 1545 Consecutive patients from primary catchment area attending for their first gastroscopy; 454 were referred through the outpatient clinic or by hospital colleagues (clinic group) and 1091 were accepted for endoscopy solely on their general practitioner's clinical diagnosis (open access group).

Results-Similar numbers (about $40 \%$ ) of examinations with normal findings were performed in each group, although in patients aged over 40 the proportion with normal findings was significantly higher in the clinic group $(p<0 \cdot 03)$. Endoscopic evidence of gastro-oesophageal reflux disease, peptic ulceration, and gastroduodenal inflammation was equally common in each group; upper gastrointestinal malignancy, however, was significantly more common in patients referred through hospital doctors $(5 \%, 23 / 454 v 2 \%, 22 / 1091$ respectively; $\mathbf{p}<\mathbf{0 . 0 0 5}$ ) (although many of these patients had already been extensively investigated).

Implications - Open access gastroscopy does not increase the number of unnecessary examinations and should become more widely available. Targeting this service to patients aged over $\mathbf{4 0}$ would reduce the number of requests but increase the diagnostic yield.

\section{Introduction}

Providing general practitioners with free or open access to upper gastrointestinal endoscopy services offers patients the opportunity of rapid diagnosis and treatment. It also reduces the burden on hospital outpatient departments' and minimises diagnostic endoscopy in patients who have already been treated by the time the examination is eventually performed. Many endoscopy units, however, are reticent about permitting such access, fearing a massive increase in workload and an unacceptable increase in the number of "unnecessary" examinations, which disclose normal findings. It has been proposed that the application of diagnostic scoring systems ${ }^{23}$ by general practitioners might lead to more selective open access referral patterns, but such systems are commonly cumbersome and even simple systems may fail to gain wide acceptance in a busy surgery. The aim of this study was to elucidate whether unselected open access gastroscopy generates excessive numbers of examinations with normal findings. In addition, as it has been claimed that the investigation of dyspepsia in younger patients rarely influences management ${ }^{4}$ we have stratified our data by age and assessed the effect on endoscopic yield of targeting endoscopy resources in older groups of patients.

\section{Subjects and methods}

An open access gastroscopy service has been available at Halton District General Hospital since 1986. Local general practitioners were informed of the service by letter and were sent regular reminders several times each year. In a retrospective audit of a single consultant's (GHH) gastroscopy practice we compared the endoscopic findings in 1091 unselected patients (581 males, 510 females) accepted for their first gastroscopy solely on the clinical diagnosis of their general practitioner with those in 454 patients (193 males, 261 females) referred internally (through the outpatient clinic or by other hospital colleagues). The age distribution of the two groups was similar (median age (range) 48 (13-91) years and 51 (14-92) years respectively).

A $\chi^{2}$ test was used to compare differences in the prevalence of upper gastrointestinal disease and in the proportion of abnormal and normal findings on gastroscopy in each group. In examinations in which bile reflux was present in a stomach with normal mucosa the findings were reported as normal; analysis of our data taking simple bile reflux as an abnormal finding did not alter our conclusions.

\section{Results}

Table I summarises the endoscopic findings. Accepting unselected patients for upper gastrointestinal endoscopy did not result in an increase in the proportion of examinations that disclosed normal findings. Furthermore, the proportions of patients with gastro-oesophageal reflux disease (hiatus hernia, oesophagitis, benign ulceration, and stricture) and 